\title{
Celebrity Philanthropy in Mainland China
}

\section{ELAINE JEFFREYS*}

University of Technology Sydney

\begin{abstract}
Celebrity philanthropy in mainland China is a recent phenomenon that has attracted both media publicity and public controversy. Despite its visibility, few data exist regarding how widespread the phenomenon is, and whether it has been growing over time. This paper addresses this gap, using a sample of entertainment and sports celebrities obtained from publicly available sources to answer three key questions. What proportion of celebrities in mainland China engage in philanthropic activities? When did they become involved in philanthropic activities? With what kinds of philanthropic causes and organisations are they connected, and in what capacity? The paper reveals that, in a very short period of time, mainland China's top celebrities have become just as involved with philanthropic causes as their North American counterparts. The rapid rise of celebrity philanthropy has been correlated with a series of natural disasters and the explicit encouragement of government authorities, offsetting the absence of a tradition of private charitable activities in the People's Republic of China since its founding.
\end{abstract}

Keywords: China, celebrity, celebrities, charity, Chinese, government, media, philanthropy

\footnotetext{
*Correspondence Address: Elaine.Jeffreys@uts.edu.au
} 


\section{Introduction}

The growth of "celebrity philanthropy" in western liberal-democratic societies since the 1990s, whether referring to celebrity endorsement of public charities, celebrity donors or celebrity-funded private foundations, is an increasing focus of academic attention. Studies typically focus on the rise and consequences of celebrity philanthropy in western societies, especially in the United States (US) - the "home" of capitalism and big-money philanthropy. Supporters argue that leveraging "fame" helps to raise the public profile of a given social issues campaign and its host organisation by bringing extra media coverage, attracting new audiences, demystifying campaign issues, encouraging sponsorship, raising public awareness and encouraging civic engagement (Bishop and Green, 2008). Critics insist that celebrity philanthropy rationalises inequality and is "fundamentally depoliticising" because it disguises the exploitative nature of trade and business relationships, and is driven by media desires for a story and the imperatives of the celebrity industry (Kapoor, 2013, p. 1). Whichever the case may be, there has been little research to date on celebrity philanthropy in developing countries.

This paper examines the growth of celebrity philanthropy since the mid-2000s in the People's Republic of China (PRC), an emerging economy where "philanthropy" - the planned and structured giving via a non-profit business model of "money, time, information, goods and services, voice and influence to improve the wellbeing of humanity and the community" - is a recent phenomenon. ${ }^{1}$ Unlike in western societies (and in Hong Kong), the non-profit sector and elite philanthropy in mainland China refer to new professions, organisations and social actors that are simultaneously coming into being, largely at the behest of an authoritarian government, to enhance social service provision. Hence, contrary to conventional understandings of the nonprofit sector, and especially non-governmental organisations (NGOs), as essential 
Author copy, 1 July 2015, published in Asian Studies Review, 39, 4: 571-88 (DOI:10.1080/10357823.2015.1081871).

agents of civil society and democracy, the development of China's non-profit sector is intimately bound up with government-led efforts to create a new public culture of philanthropy.

The imbrication of China's philanthropic sector with the PRC government may be viewed as "undesirable" from the perspective of idealised conceptions of a civil society, potentially hindering the organic development of NGOs and even legitimising (unequal) wealth concentration and elite power structures (Carrillo, 2012; Kapoor, 2013). Analyses that commence with this assumption run the risk of falling into the trap that Dipesh Chakrabarty (2000, p. 6) brands a variety of "historicism" - that is, of viewing history as something that happens "first in the West, and then elsewhere". Such an approach tacitly prioritises the path of development that philanthropy has taken in western societies over alternative possible trajectories that it can and does follow in developing countries. To avoid this trap, this paper seeks to avoid comparisons to idealised notions of how philanthropy should be organised institutionally and instead aims to shed light on the main factors that are encouraging the development of celebrity philanthropy in China today.

The discussion proceeds as follows. I first explain why the concepts of "philanthropy" and "celebrity" had no meaning in the PRC prior to the adoption of market-based economic reforms in December 1978. I then track the rapid expansion of mediatised celebrity philanthropy in the PRC since the mid-2000s with reference to an empirical study of 145 mainland Chinese celebrities. Analysis of the causes supported by these celebrities demonstrates that celebrity philanthropy in China developed chiefly in response to humanitarian crises such as the 2008 Sichuan earthquake. It also shows that government support for the accelerated development of philanthropic organisations and elite philanthropy - in part to remedy welfare gaps that have appeared amid the decline of the "socialist welfare state" and rise of the market economy - has played an important role. Moreover, it appears that, notwithstanding the short history of philanthropy in the PRC, mainland China's top celebrities are just as involved with philanthropic causes as their North American counterparts, based on a similar study of the extent of celebrity philanthropy in the US (Thrall et al., 2008, pp. 362-85). 


\section{A Brief History of Philanthropy and Celebrity in the PRC}

"Philanthropy" and "celebrity" in the contemporary sense of those words did not exist in mainland China until after the PRC government abandoned socialist, centralised economic planning in favour of market reforms. Following the PRC's founding under the leadership of the Chinese Communist Party (CCP) in 1949, revolutionary hostility ensured that imperial- and Republican-era elite groups - landed gentry; entrepreneurs; and opposing political, military, religious and cultural figures - ceased to exist as significant agents of governance, drivers of economic enterprise and formers of local opinion. During the Mao era (1949-76), private enterprise and the private accumulation of wealth were held in check by controls over the monetary economy, the nationalisation of industry, agrarian land redistribution and state ownership and allocation of public resources. Citizens of "New China" were given food, housing, employment, health care and education, albeit typically in basic forms, through the rural agricultural collectives and urban work-unit system. Additional services were provided for people affected by natural disasters, households experiencing hardship, and revolutionary soldiers and their families (Wong, 1994, pp. 311-12). These forms of state-provided welfare were not described as charity/philanthropy (cishan) but rather as services (fuwu) relating to care (guanhuai zhaogu), welfare (fuli), relief (jiuji) and allowances $(b u z h u)$.

State control over the broadcast media also guaranteed that China's media served as the "voice" of the CCP, communicating Party-state ideology and policies and promoting revolutionary heroes as public role models. Hence, the only identifiable elite group in the early PRC consisted of Communist Party members in official posts and CCP-endorsed PRC-supporters. New elite groups, composed of private entrepreneurs and commercial sports stars and entertainment celebrities, have emerged in the reform period, along with the development of a market economy and an increasingly commercialised media (Edwards and Jeffreys, 2010; Goodman, 2008).

The absence of "philanthropy" in the early PRC is highlighted in a 1994 report by Sun Yuemu in the People's Daily, the official media voice of the CCP, about the 
Author copy, 1 July 2015, published in Asian Studies Review, 39, 4: 571-88 (DOI:10.1080/10357823.2015.1081871).

establishment of the Liaoning Provincial Charity Federation. Sun (1994, p. 4) notes that the newspaper's readers were probably seeing the Chinese-language character "cishan", which translates into English as both "charity" and "philanthropy", for the first time. The character was recorded in the sixth-century chronicle Book of Wei, and entered into colloquial speech via Japan in the early twentieth century as a word to describe charities run by foreign missionaries in particular (Li, 2009), but the concept and practice of charity/philanthropy fell into disrepute after 1949. In fact, some historians of charity in China claim that during the height of the Mao era - the now reviled Great Proletarian Cultural Revolution (1966-76) - charity was denounced as a "feudal poison" and the "sugar-coated bullet" of the bourgeoisie (Zhou and Zeng, 2006, p. 368). In other words, organised charity which no longer existed in the PRC allegedly was condemned in Marxist terms as the means by which elite groups attempted to prevent class struggle by placating the proletariat. Sun Yuemu (1994, p. 4) concludes that the "good name" of "charity" had been rehabilitated in reform-era China to assist (not to replace) the state in meeting new social needs. The Charity Federation's mission was to promote the development of domestic and international charities to help the government provide social services for "the most pitiable" members of society - that is, impoverished, disabled and elderly people, with no family members to look after them.

The development in the PRC of western-style conceptions of philanthropy can thus be dated from the mid-1990s. This conclusion is confirmed by a search for the keyword "cishan" in the People's Daily between 1949 and 2012. The search obtained fewer than 3,500 hits, with fewer than 600 hits before 1991; nearly 3,000 hits occurred after 1990, and more than 2,000 of those were in the 2000s (People's Daily, 1946-present).

These figures indicate that in the wake of policies that decentralised the economy, underpinning rapid economic growth at the expense of widening inequality, a space was created for philanthropies and private service providers to supplement the role of government in the provision of social services, mitigate wealth disparities and reduce the potential for social unrest. The gradual dismantling of the agricultural collectives and urban work-units undermined the state's ability to supply the depth of services to employees and retirees that had previously been the norm. Efforts to upgrade social 
Author copy, 1 July 2015, published in Asian Studies Review, 39, 4: 571-88 (DOI:10.1080/10357823.2015.1081871).

service provision acquired a new urgency in this context. The PRC government now faced the expensive option of having to create a "modern" welfare system from scratch, and make available a full range of standardised services such as health, disability, maternity, unemployment and retirement assistance to all citizens, via government, community and private service providers (Watson, 2012, p. 265; Wong, 1994, pp. 311-23).

Since the 2000s, the PRC government has attempted to enhance social service provision in part by making the development of professionalised philanthropy an object of national policy. China's Tenth Five-Year Plan for National Economic and Social Development (2001-05) recommended developing philanthropic enterprises to supplement the inadequate social security system in the context of an ageing population (National People's Congress, 2001, Section 3, Chapter 8). The Eleventh Five-Year Plan (2006-10) proposed expanding philanthropies in general, especially those supporting education and homeless children (National People's Congress, 2006, Section 4, Chapter 28). The Twelfth Plan (2011-15) recommended using tax incentives to massively expand China's non-profit sector by creating a system of registered private industry, trade and professional associations, and urban and rural community organisations, to support, and perhaps even supplant, some government welfare functions by providing private services for disadvantaged, disabled, elderly and orphaned people (National People's Congress, 2011, Section 1, Chapter 39).

The PRC government has subsequently altered the regulatory framework controlling organised philanthropy in China to encourage the rapid development of an indigenous non-profit sector, while maintaining restrictions on foreign NGOs and donors (Fitzgerald, 2012, pp. 75-78). Government-organised non-governmental organisations (GONGOs) dominated China's non-profit sector until recently because the first regulations governing the management of foundations and social organisations, which were issued in 1988 and 1989 respectively, required philanthropies to register with relevant government departments and to be sponsored by a government agency (Shieh, 2011, p. 6). GONGOs could register more easily than other types of organisations because they were sponsored by the government agency that established them (Shieh, 2011, p. 6). 
In 2012, the central government allocated funds of CNY 200 million to support the development of domestic NGOs (He, 2012, p. 3). Pilot programs were established in 19 provinces that allowed NGOs to register directly with civil affairs departments and apply for government funding, rather than first having to find a sponsoring government organisation. In 2013, the Anhui provincial government, and the Beijing and Guangzhou municipal governments sought to encourage the organisation of NGOs independent of government intervention by introducing provisional regulations banning government officials from joining NGOs. ${ }^{2}$ These changes herald a new degree of separation between "government" and "society", with Chinese media reports indicating that the PRC's legislature will review a draft Charity Law, which has been drafted and debated numerous times since 2005, at the end of 2015 ('Charity law draft expected to be reviewed in 2015', 2015).

The PRC's Ministry of Civil Affairs has also promoted philanthropy since 2005 through a system of prestigious annual charity awards (Zhonghua cishan jiang). Awards are presented to government officials and other individuals for their charitable activities, with private entrepreneurs and leaders of state-owned enterprises receiving awards for the recorded extent of their donations. Hu Jintao (PRC President, 2002-12) became the first leader of the PRC to present philanthropy as important to China's modernisation when he announced the winners in December 2008. Hu's speech was delivered in the aftermath of the May 2008 Sichuan earthquake, a catastrophe estimated to have killed 70,000 people and which left 5 million homeless. The earthquake also led to a massive increase in public donations, with the amount of money donated in China in 2008 alone eclipsing the total for the previous decade (Liu, 2008; Wang, 2008). In a speech described by the People's Daily as a mobilisation directive, President Hu enjoined China's citizens to develop a philanthropic culture without delay to help achieve a relatively "well off" and harmonious China (Liu, 2008).

Although celebrities have received these awards, commercial entertainment and sports stars are more commonly listed on the China Charity Ranking (Zhongguo cishan bang), launched by the China Philanthropy Times in 2005 (www.gongyishibao.com). 
The China Philanthropy Times is sponsored by the Chinese Association of Social Workers under the guidance of the Ministry of Civil Affairs. The Rankings recognise corporations and entrepreneurs according to the documented extent of their donations. Entertainment and sports celebrities are celebrated for raising public awareness of philanthropic causes through media publicity. Another magazine called the Chinese Philanthropist (Zhongguo Cishanjia), which is run by an independent non-profit venture, issued its first China Celebrity Philanthropist list in 2013 (Zhongguo cishan mingren bang) (www.icixun.com). The proliferating nature of such awards points to a growth in mediatised celebrity philanthropy.

The rapid growth of Chinese press interest in celebrity philanthropy since the mid2000s is illustrated in Figure 1. Data was obtained by conducting a search for the keywords "cishan" (charity/philanthropy) and "mingxing" (celebrity) on the China Core Newspaper Full-text Database of the China Knowledge Resource Integrated Database (CNKI), a database of over 500 Chinese newspapers since 2000 (cnki.net.cn). The left-hand side of the figure indicates that Chinese press coverage of the words "charity/philanthropy" and "celebrity" has grown significantly since 2000 (by three times and twenty times respectively). The right-hand side indicates that Chinese press coverage of the words "celebrity philanthropy" has also grown significantly since 2000 , albeit at a lower level in terms of absolute numbers of hits.

\section{INSERT FIGURE 1 NEAR HERE}

\section{Figure 1: Chinese Newspaper Coverage of "Celebrity" and "Philanthropy"} (2000-13)

Chinese media interest in celebrity philanthropy reflects not only the growth of a commercial celebrity industry, but also the dominance of government-affiliated charities in China. Celebrity agents typically liaise with large charities, which have the staff and resources needed to handle celebrities, and the biggest charities in China are either GONGOs or government-endorsed international NGOs (INGOs) (see below). Government policies and censorship controls also encourage Chinese media organisations to provide positive coverage of particular social issues at particular times (and to neglect others). For example, the PRC's Five-Year Action Plan for Controlling, 
Preventing and Treating HIV/AIDS (2011-15) encourages the use of celebrities in "easy-to-understand" public service announcements about HIV prevention (Guowuyuan bangongting, 2012).

Although the PRC government encourages positive media coverage of philanthropy, the motivations and "authenticity" of China's celebrities as donors and fund-raisers has been criticised in multiple media. International film star, Zhang Ziyi, became the focus of widespread media coverage and public condemnation in 2010 after she allegedly defaulted on a pledge to donate CNY 1 million to the Sichuan earthquake disasterrelief fund (Jeffreys, 2011, p. 4). Other entertainment and sports stars were similarly accused in online forums of "dishonest advertising" or failing to deliver on publicised pledges (Jeffreys, 2011, pp. 10-15). Such controversy not only points to mounting conflict over wealth distribution in the context of China's transforming economy, but also brings into question the assumption that celebrity philanthropy is an easy, selfserving and "unaccountable" way of obtaining publicity and staying famous (e.g. Kapoor, 2013).

Despite its visibility, few data exist regarding how widespread the phenomenon of celebrity philanthropy is at the national level in mainland China, and whether it has been growing over time. This paper addresses this gap by using a sample of mainland Chinese celebrities in entertainment and sports obtained from publicly available sources to answer three key questions. What proportion of mainland Chinese celebrities engage in philanthropic activities? When did they become involved in philanthropic activities? What kinds of philanthropic causes and organisations are they connected with, and in what capacity?

\section{Methodology}

In order to determine the extent and nature of celebrity philanthropy in contemporary China, a sample of mainland China's celebrities in entertainment and sports was obtained by combining five 'Top Chinese Celebrity' lists in 2011, and then removing the names of non-mainland Chinese celebrities and all duplicate names. This process resulted in a sample group of 145 mainland Chinese celebrities (74 women and 71 
Author copy, 1 July 2015, published in Asian Studies Review, 39, 4: 571-88 (DOI:10.1080/10357823.2015.1081871).

men). The five lists accessed on 1 July 2011 were: Forbes' China's Top 100

Celebrities; Baidu's Today's Top 50 Female Celebrities (Jinri nümingxing

paihangbang); Baidu's Today's Top 50 Male Celebrities (Jinri nanmingxing

paihangbang); Sogou's Mainland China's Top 60 Female Celebrities (Remen dalu

nümingxing TOP60); and Sogou's Mainland China's Top 60 Male Celebrities (Remen

dalu nanmingxing TOP60). Although the two Sogou lists contained a larger number of marginally less well-known celebrities than the Forbes or Baidu lists, it is worth noting that the sample is skewed towards major celebrities. The Forbes and Baidu lists use, respectively, individual income and media exposure, and internet keyword searches, to develop hierarchical rankings of celebrities (Forbes Staff, 2011), which by construction tends to limit the representation of "minor" celebrities.

The extent and nature of the involvement of mainland Chinese celebrities with philanthropic causes was determined by conducting an Internet search on Google and Baidu, using the name of each celebrity and search terms for philanthropy to find news stories, links and webpages mentioning their philanthropic activity. The search terms used to find evidence of celebrity involvement in philanthropic activities were: “philanthropy/charity” (cishan), "public welfare/charity” (gongyi), “care/compassion" (aixin) and "donation" (juan). These search terms generated content about celebrity philanthropy-related activities in the broadest sense. That content was analysed to determine the kinds of philanthropic causes that mainland Chinese celebrities are involved with and the nature of their involvement.

\section{China's Celebrity Philanthropists and their Causes}

The results confirm that celebrity philanthropy is a recent but widespread phenomenon in mainland China. Of the sample of 145 celebrities, 138 celebrities or 95 per cent of the total had a publicised record of philanthropic engagement. Most of the celebrities in the sample group engaged in their first publicised philanthropic activity after 2004, with only three having a public record of philanthropy prior to the 2000s. ${ }^{3}$

Reports on the growth of philanthropy in the PRC usually link that growth to the disaster-relief efforts associated with the 2004 Indian Ocean tsunami and two major 
Author copy, 1 July 2015, published in Asian Studies Review, 39, 4: 571-88 (DOI:10.1080/10357823.2015.1081871).

natural disasters in China in particular - the 2008 Sichuan-Wenchuan earthquake and the 2010 Yushu earthquake (Bao, 2009; Deng, 2011; Fullbrook, 2005). Figure 2 confirms that there is an empirical basis for this assertion, showing that 40 celebrities from the sample group engaged in their first publicised philanthropic activity in 2008, and that 28 celebrities engaged in their first publicised activity in 2010 . The numbers are considerably lower for other years: one celebrity engaged in their first publicised philanthropic activity in 2003 and eight celebrities engaged in their first publicised activity in 2004 and 2009 respectively.

\section{INSERT FIGURE 2 NEAR HERE}

\section{Figure 2: Development of Chinese Celebrity Philanthropy}

The results also provide a snapshot of the "typical" Chinese celebrity philanthropist. As of late 2011, the 138 publicly active celebrity philanthropists (72 women and 66 men) in the sample had engaged on average with three philanthropic causes. One of these celebrities was a child, 11 were over 50 years of age, 21 were in their forties, 50 were in their thirties, and 55 were in their twenties. The average age of the 72 women was 32 years and the average age of the 66 men was 37 years. Thus the "typical" celebrity philanthropist in mainland China in 2011 was 34 years of age and engaged in three philanthropic causes, with women and men having a more or less equal record of philanthropic engagement. Celebrity philanthropists in China, as elsewhere, are therefore younger and marked by a more equitable gender mix than the stereotypical elite philanthropist (corporate male aged over 50) (Ostrower, 1995, pp. 69-85), with an associated capacity to contribute to the expansion of the non-profit sector through media publicity of their philanthropic donations and advocacy.

The figures regarding mainland Chinese celebrities' involvement in philanthropic activities may be compared to those reported in a study of celebrity philanthropy in the US conducted by A. Trevor Thrall et al. (2008). The US study is based on a random sample of 147 celebrities from Celebopedia.net, an online encyclopaedia of entertainment and sports celebrities, and an examination of the 2006 Forbes 100, a list of the top-ranking celebrities in the US. Thrall et al. (2008, pp. 367-68) concluded that 62.8 per cent of the sample group of US celebrities from Celebopedia engaged in 
Author copy, 1 July 2015, published in Asian Studies Review, 39, 4: 571-88 (DOI:10.1080/10357823.2015.1081871).

philanthropy, with each celebrity philanthropist involved on average with 1.8 causes or issues, and 90 per cent of the US celebrities on the Forbes 100 list engaged in philanthropy with an average of 4.16 issues. They attribute the higher percentage of philanthropic engagement associated with celebrities from the Forbes 100 list to the fact that they are "bigger names" with more "star power" and capacity to attract media attention.

In comparison, 90 per cent of the mainland Chinese celebrities on the combined Baidu and Sougou lists engaged in philanthropic activities, with each celebrity philanthropist involved on average with 3.4 causes, and 100 per cent of the celebrities on the 2011 Forbes China's Top 100 Celebrities list engaged in philanthropic activities, with an average of 3.7 causes. Hence, mainland China's top celebrities are just as likely to provide public support for philanthropic causes as their western counterparts. This is a remarkable development given the short history of philanthropy in the PRC. A caveat here is that the nature and quality of that involvement may vary considerably, both within China and across countries, and such an analysis is beyond the scope of this study.

Celebrity involvement in philanthropic causes in mainland China can be divided into 11 broad categories. In Figure 3, the relative degree of celebrity involvement in these causes is indicated in percentages, with multiple entries allowed for each celebrity to capture the different issues that they promote. Hence the numbers provided add up to more than 100 per cent.

The causes most supported by the publicly active celebrity philanthropists were disaster relief (63 per cent) and welfare programs for children (55 per cent). Other causes attracting a high level of support were: poverty alleviation, including development programs aimed at providing potable water and food supplies for disadvantaged groups and communities (46 per cent); education, especially for children in poor rural areas and the children of rural-to-urban migrants (41 per cent); and health, including improving treatment and support services for people living with conditions such as HIV, AIDS, leukaemia and depression (also 41 per cent). Causes that attract a lower degree of support were: environment and general conservation causes, such as 
Author copy, 1 July 2015, published in Asian Studies Review, 39, 4: 571-88 (DOI:10.1080/10357823.2015.1081871).

promoting "green" practices and energy efficiency (30 per cent); women and girls as the recipients of targeted aid programs delivering water, health and basic services (26 per cent); and youth, especially improving access to tertiary education and health care (14 per cent). The causes least supported by the sample group of celebrity philanthropists were: support for the elderly ( 9 per cent); animal protection (also 9 per cent); and activities to support disabled people (5 per cent). Male and female celebrities were generally evenly represented across all of the 11 categories.

\section{INSERT FIGURE 3 NEAR HERE}

\section{Figure 3: Celebrity Causes}

The nature of celebrity support for philanthropic causes in mainland China can be compared to that observed in the US by Thrall et al. (2008). There are some differences between the categories used in the two studies. Thrall et al. (2008, p. 367) include categories such as "economics" and "politics", which only received the limited support of 2 per cent and 4 per cent of celebrities in the US, but simply did not emerge in the survey of mainland Chinese celebrities because of state controls associated with the PRC's one-ruling-party system. Conversely, Thrall et al. (2008) do not refer to the category of disaster relief, which is the most prominent philanthropic cause supported by celebrities in China (advocated by 63 per cent). Even the category of "foreign assistance" used by Thrall et al. (2008), for which no exact counterpart exists in the present study, only attracted the efforts of 11 per cent of celebrities in the US sample.

These discrepancies aside, the two studies reveal that welfare and health programs for children represent a key area supported by celebrities in both countries ( 55 per cent in the PRC and 52 per cent in the US), followed by social welfare (46 per cent in the PRC and 45 per cent in the US) and health (around 41 per cent in both countries) (Thrall et al., 2008, p. 367). Animal protection received a roughly similar degree of support in both countries ( 9 per cent in the PRC compared to 8 per cent in the US). Education received more support from celebrities in the PRC (41 per cent) than from those in the US (10 per cent), as did environmental causes (30 per cent in the PRC compared to 10 per cent in the US). These higher rates reflect the preponderance of non-profits focused on education and the environment in the PRC whose work typically complements state 
Author copy, 1 July 2015, published in Asian Studies Review, 39, 4: 571-88 (DOI:10.1080/10357823.2015.1081871).

goals of improving education opportunities and tackling (in politically non-confronting ways) the environmental degradation that has accompanied rapid economic growth (Hildebrandt, 2011, p. 972).

While the results of the mainland China survey highlight the range of roles performed by celebrities as philanthropists, they also underscore the dominance of GONGOs and INGOs in the PRC's non-profit sector. Nearly 70 per cent of the publicly active celebrity philanthropists engaged in philanthropic activities that were linked to 110 charities, comprising 90 domestic organisations and 20 international organisations. The links between celebrities and philanthropies were established by counting a broad range of activities whereby both the celebrity and the organisation were linked via media publicity. These links are described as instances of celebrity support because some celebrities attracted multiple counts through being involved with a particular charity in different capacities or on different programs with the same organisation. Celebrities supported these organisations by engaging in a wide range of activities, including: donating to a specific charity; attending charity galas, auctions and fundraising drives; holding benefit concerts; allowing their image to feature in special stamp collections for charity; producing songs that generated awareness of specific issues; and visiting disadvantaged persons and areas.

A total of 56 celebrities ( 31 men and 25 women) had 110 documented instances of acting as official ambassadors for philanthropic initiatives, using titles such as public welfare spokesperson (gongyi huodong daiyanren), care ambassador (aixin dashi) and image ambassador (xingxiang dashi). Some celebrities also acted as the "face" of charitable corporate social responsibility (CSR) initiatives, including activities run under the auspices of media organisations, such as television fundraisers. However, examples of celebrity involvement with CSR initiatives run by for-profit organisations were removed from the sample for the purposes of this study to focus on instances of celebrity support for the non-profit sector.

The most popular domestic charities in the PRC, based on the number of times an organisation was linked to the sample of 138 publicly active celebrity philanthropists, are GONGOs. Male and female celebrities offered roughly equal amounts of support 
Author copy, 1 July 2015, published in Asian Studies Review, 39, 4: 571-88 (DOI:10.1080/10357823.2015.1081871).

for the 12 charities discussed below, eight of which featured on a list of China's top 25 charities in 2011 (Lin, 2011). Three GONGOs focused on disaster relief, education and poverty alleviation attracted more than 10 instances of celebrity support respectively: the Red Cross Society of China (RCSC); the China Youth Development Foundation (CYDF); and the China Foundation for Poverty Alleviation. The China Charity Federation, a GONGO that assists orphaned, elderly and disabled people and focuses on disaster relief, education and health care, had nine instances of celebrity support. Three charities attracted six instances of celebrity support: two GONGOs that assist women and children - the China Women's Development Foundation and the All-China Women's Federation; and a foundation established by actor Jet $\mathrm{Li}$ - the One Foundation, which promotes philanthropy and focuses on disaster relief, poverty alleviation, education, health and the environment. The Shanghai Charity Foundation, a GONGO that assists orphans, street children, and widowed and disabled people, attracted celebrity support in five instances. Four organisations attracted three instances of celebrity support: two GONGOs: the All-China Federation of Trade Unions, which provides services for labourers; and the China Soong Ching Ling Foundation, which promotes domestic welfare and "friendly" international relations; and two foundations: the Shanghai More Love Foundation, which focuses on disaster relief and education; and the celebrity-founded Smile Angel Foundation, which assists children born with cleft lips and palates.

Around 15 per cent of the publicly active celebrity philanthropists in mainland China engaged in philanthropic activities that were linked to INGOs, on 33 occasions. The most popular international organisation was the United Nations Children's Fund (UNICEF) (13 instances of celebrity support). The first recorded instance of mainland Chinese celebrity engagement with UNICEF was in 2005 when actor-singer Zhao Wei acted as an ambassador for its "Caring for Children Affected by AIDS" initiative (Wu, 2005). Since then, celebrities have been linked to a wide range of UNICEF initiatives, including appearing at special events and on promotional calendars, visiting disaster areas and victims, making public donations, and acting as ambassadors for specific programs. Other international organisations that feature in the sample include: the World Wildlife Fund (8 instances of celebrity support), chiefly in the context of Earth Hour activities; the International Labour Organisation (3 instances); and the United 
Author copy, 1 July 2015, published in Asian Studies Review, 39, 4: 571-88 (DOI:10.1080/10357823.2015.1081871).

Nations' Environment and Development Programs (2 instances respectively). Slightly more support from female celebrities than male celebrities was documented for these international organisations (23 versus 10 instances).

While the preceding discussion demonstrates celebrity support for an established system of GONGOs and INGOs, the next section indicates the potential for the PRC's non-profit sector to expand in more heterogeneous ways by looking at celebrity-funded private foundations. An examination of these foundations reveals a diversification of organisational forms and funding models.

\section{Celebrity Foundations/Funds}

Private foundations provide the basis for elite philanthropy in developed countries such as the US, which had an estimated 86,000 private foundations in $2013,{ }^{4}$ but the groundwork for the establishment of a private philanthropy sector in the PRC was only laid on 1 June 2004 when the Regulations on the Management of Foundations (Jijinhui guanli tiaoli) came into effect (State Council, 2004). The "2004 Regulations" changed the structure of the PRC's non-profit sector by allowing the registration of two different types of foundation: "public fundraising foundations" (gongmu jijinhui), which can raise funds from the public, and "non-public fundraising foundations" (feigongmu jijinhui), which are not permitted to raise funds publicly, and have to rely on private funding from individuals and organisations (State Council, 2004, Article 3). "Public fundraising foundations" generally refer to GONGOs, while "non-public fundraising foundations" generally refer to "private foundations" - that is, foundations established with funding from wealthy individuals and private corporations, although there are exceptions (Shieh, 2011, p. 2). In 2004, there were fewer than 900 registered public foundations and no private foundations in the PRC (Shieh, 2011, p. 6). By 2012, there were more than 3,000 foundations, comprising over 1,300 public fundraising foundations and nearly 1,700 non-public fundraising foundations (Ministry of Civil Affairs of the PRC, 2013). In other words, although the PRC statistics are tiny when compared to the US figures, there are now more "private" foundations in mainland China than there are government-operated foundations. 
The growth of foundations in mainland China may be interpreted in different ways. Viewed positively, it has the potential to provide an alternative source of funding for NGOs, encourage a focus on neglected areas or issues other than those backed by government, and improve professional standards and financial transparency (Shieh, 2011). Viewed negatively, it legitimises wealth concentration and the political status quo by suggesting that "the rich can save the world" (Carrillo, 2012; Kapoor, 2013). Whichever the case may be, the number of celebrity-funded or celebrity-founded foundations derived from the sample group is too limited to support any grand conclusions. An examination of these foundations highlights instead a range of organisational forms and funding models.

A total of 13 celebrities from the sample group established their own philanthropic foundations or funds between 2004 and 2011, with both genders equally represented. Eleven celebrities from the sample established a self-managed organisation; and four celebrities established charitable projects managed by registered charities, chiefly GONGOs. These figures include multiple counts for two male celebrities who founded two different charitable organisations respectively, and one count for a female actor who co-founded a charitable organisation with one of them. A third type of celebrity charity is excluded from discussion on the grounds that the celebrities in question may have little to do with them in practice. These are charitable organisations founded in the name of a given celebrity by fans, which may be self-managed or managed by a registered charity, of which there were eight examples in the sample. ${ }^{5}$

Three mainland Chinese celebrities from the sample group established private foundations in the US in 2008. Lang Lang, a male classical pianist, registered the Lang Lang International Music Foundation to further music education (langlangfoundation.org). Basketball player Yao Ming and actress Zhang Ziyi registered the US-based Yao Ming Foundation and the Ziyi Zhang Foundation respectively in response to the Sichuan earthquake, both focusing on the building of schools (theyaomingfoundation.org; Jeffreys, 2011, pp. 5-6).

Eight celebrities (five women and three men) established seven self-managed charities in mainland China, only two of which raise funds from the public. Jet Li founded the 
Author copy, 1 July 2015, published in Asian Studies Review, 39, 4: 571-88 (DOI:10.1080/10357823.2015.1081871).

One Foundation in 2007 under the auspices of the RCSC to promote philanthropy and volunteerism (onefoundation.cn/). The One Foundation made history in December 2010 when it became the first non-governmental or independent public fund-raising foundation in the PRC. Since then, the One Foundation has been receiving public donations under its " 1 person +1 dollar +1 month $=1$ big family" program, with donations being deposited into an account held by the RCSC. The foundation encourages individuals to donate one Chinese dollar per month to create a greater fund to assist the most vulnerable members of society, focusing on disaster relief, poverty alleviation, education, health and the environment.

Jiang Yiyan, a female actor and singer, is the only other celebrity to have created a self-managed charity that collects public monies, albeit via a not-for-profit commercial business model. In 2011, Jiang founded the Rovers' Education Foundation (Paxingzhe aixin zhuxue jijinhui) to support the education of seven orphans from Guangxi Province. The foundation now supports 17 orphans and is committed to supporting their education through to the end of tertiary-level education. Jiang's charity is funded by sales made through an online store that trades on Taobao.com, a Chinese version of Ebay. Established in 2009, the store raises funds for children's welfare programs in impoverished and disaster-affected regions of China through the sale of second-hand clothing items donated by Jiang and her celebrity friends (shop58393702.taobao.com).

The other five self-managed domestic celebrity charities rely on donations from their celebrity funders. In 2004, female actor Zhao Wei donated CNY 300,000 to establish the Zhao Wei Scholarship Fund (Zhao Wei jiangxue zhuxue jijin) in partnership with the Wuhu Education Department. ${ }^{6}$ The Fund assists impoverished children to complete schooling in Zhao's birthplace of Wuhu city, Anhui province. Song Zuying, an ethnic minority folk singer from a poor, rural family background, similarly founded the Song Zuying Education Fund (Song Zuying zhuxue jijin) in 2005 to help impoverished children in Hunan Province go to school (Zheng, 2004). In 2005, Yang Lan, a talkshow host and media entrepreneur, founded the Sun Culture Foundation (Yanguang wenhua jijinhui) with her partner $\mathrm{Wu}$ Zheng, to promote Chinese arts, culture and philanthropy (www.sunculturefoundation.com). In 2006, Guo Jingming, author and editor of the popular youth magazine series "Top Novel" (Zuixiaoshuo), founded the 
Author copy, 1 July 2015, published in Asian Studies Review, 39, 4: 571-88 (DOI:10.1080/10357823.2015.1081871).

Top Novel Fund with his publisher, contributing 1 per cent of the magazine's profits to support people in need (Xu, 2007). In 2011, actors Huang Xiaoming, Huang Shengyi and Yang Zi co-founded the "Sun Action" Cataract Fund for the Elderly ("Yangguang xingdong" laonian baineizhang cishan jijin). ${ }^{7}$

Yang Lan, the celebrity founder of the Sun Culture Foundation (SCF), merits special attention for playing a public role in promoting elite philanthropy in China with international connections. Ranked number 56 on the Forbes China's 100 Richest Business People list in 2011, ${ }^{8}$ Yang Lan hosted a forum on philanthropy organised by the SCF and the Bill and Melinda Gates Foundation in Beijing in September 2010. That forum and the subsequent reception dinner attracted widespread media publicity and debate, being attended by US billionaire-philanthropists Bill Gates and Warren Buffett and around 50 of China's wealthiest entrepreneurs (Xinhua News Agency, 2010). Gates and Buffett talked about their involvement in the Giving Pledge, a campaign that invites the world's wealthiest individuals and families to commit publicly to giving at least half of their wealth to effective philanthropic causes of their choice either during their lifetime or immediately after their death (givingpledge.org).

Four male celebrities from the sample group established charitable projects in China that are managed by GONGOs or the One Foundation. Two charities were established in 2008 in response to the Sichuan earthquake. Huang Xiaoming established the Healthy Children's Home Fund (Ankang ertong jiayuan zhuanxiang jijin), which is managed by the China Children and Teenagers Fund (Zhongguo ertong shaonian jijinhui) (www.aqyjw.com/hxmak/Default.aspx); and Yao Ming established the Yao Ming Foundation (China), under the auspices of the CYDF (yaofoundation.cn). In 2010, comedian Zhou Libo (and his wife) established the Hi-pipe Talk Show Foundation (n.d.) under the auspices of the Shanghai Charity Foundation to support outstanding school students. Also in 2010, actor Wen Zhang established the Dafu Care Autism Fund (Dafu zibizheng guan'ai jijin) in honour of "Dafu", the autistic protagonist he played in the award-winning film Haiyang Tiantang (Ocean Heaven) (dir. Xue Xiaolu, 2010). Ocean Heaven is about a single father, played by actor Jet Li, who is terminally ill and has a son with autism. The Dafu Care Autism Fund is 
Author copy, 1 July 2015, published in Asian Studies Review, 39, 4: 571-88 (DOI:10.1080/10357823.2015.1081871).

managed by the One Foundation and aims to support national-level autism organisations and families affected by autism. ${ }^{9}$

Apart from foundations established to support the 2008 disaster-relief efforts, the missions of celebrity foundations/funds clearly align with the PRC government's policy goals articulated in the three Five-Year Plans for 2001-15 of providing education and assisting disadvantaged, elderly and disabled people, and promoting philanthropy (National People's Congress, 2001; 2006; 2011). Thus, natural disasters and active encouragement by high-level government authorities appear to have provided a large boost to philanthropic activity by celebrities in China in recent years.

The close correlation between government policy objectives and the missions of celebrity-funded foundations suggests that the growth of private foundations in the PRC may not necessarily result in funding for issues other than those backed by government, even though it will provide additional funding sources for non-profits and perhaps help to improve professional standards. It may also support the polemical conclusion that the growth of newly rich elite groups in China will strengthen the political status quo rather than encourage positive social change (Carrillo, 2012). The examples of celebrity foundations/funds from the sample group also demonstrate the increasingly diversified nature of the PRC's non-profit sector, being comprised of international and domestic foundations of varying scales that operate on the basis of private funds, public donations and the sale of commercial products.

\section{Conclusion}

Although celebrity philanthropy is a recent phenomenon in mainland China, it appears that supporting philanthropic causes is a commonplace activity for a new generation of celebrities in the PRC. Evidence from a sample of 145 mainland Chinese celebrities suggests that celebrity philanthropists are, on average, relatively young, with an equal distribution between women and men. More than two-thirds of China's celebrity philanthropists engage in philanthropy through their support for not-for-profit organisations, especially GONGOs and INGOs. A smaller share conduct charitable 
Author copy, 1 July 2015, published in Asian Studies Review, 39, 4: 571-88 (DOI:10.1080/10357823.2015.1081871).

activities through their own foundations or funds, or establish projects that are managed by government-affiliated and independent charities.

Celebrities in the sample predominantly engage in philanthropic activities relating to the pressing domestic needs typical of a developing country in the Asia-Pacific region. The most prominent causes include disaster relief, poverty alleviation, providing education and potable water for disadvantaged sectors of the population, especially children and mothers in rural and migrant communities, and health care for people living with leukaemia and HIV/AIDS. An inspection of these activities indicates a close alignment with the PRC government's stated policy goals, as articulated in the three Five-Year Plans for 2001-15, of providing education for children, assisting people in need, and providing improved health care for aged and disabled people (National People's Congress, 2001; 2006; 2011).

The distribution and extent of celebrity philanthropy in China invites interesting comparisons with the situation in the US, in many ways the birthplace of celebrity philanthropy in the developed world. Comparisons with the study of Thrall et al. (2008) suggest that the distribution of celebrity advocacy in the two countries is remarkably similar. While recent natural disasters in China have drawn the lion's share of celebrity involvement, celebrity philanthropists in both countries are strongly focused on the welfare of children and poverty alleviation. Consistent with the PRC's system of one-party rule, there is a lack of emphasis in China on overtly "political" philanthropic causes and celebrity advocacy in general fits into the parameters established by national policies. It appears, however, that mainland China's celebrities are just as likely to provide public support for philanthropic causes as their counterparts in the US. This is a remarkable development given the recent history of philanthropy in the PRC.

The sudden rise of celebrity philanthropy in mainland China, and the wide variety of causes and organisational forms to which it has become attached in a relatively short period of time, demonstrate that the PRC did not need a tradition of philanthropy for one to become established. The close alignment of philanthropic activities with stated policy goals suggests that the government played an important role in cultivating a 
Author copy, 1 July 2015, published in Asian Studies Review, 39, 4: 571-88 (DOI:10.1080/10357823.2015.1081871).

culture of elite philanthropy. Indeed, the development of private philanthropy has been an explicit goal of national policy since the early 2000s, supplemented by other initiatives such as annual charity awards. Recent policy documents indicate continued government support for the accelerated development of domestic philanthropic organisations, underpinned by a proposed system of tax incentives, with a view to enabling these associations to supplement and eventually even take over some of the welfare-provision functions of government.

The rapid expansion of celebrity philanthropy in mainland China to date suggests that the presence of conducive government policies has helped to offset the absence of a tradition of private charitable activities since the founding of the PRC. Rather than focusing purely on comparisons of government-led development of the philanthropic sector to idealised notions of civil society in western countries, this paper has instead sought to provide an open-ended view of the mechanisms by which a philanthropic culture is being established in China. Celebrity philanthropy can take many forms, with local and global connections, including fan bases. Notwithstanding the current heavy involvement of government, this may eventually even generate different spaces for social and civic action in the PRC.

\section{Acknowledgments}

This research was supported under the Australian Research Council's Future Fellowship funding scheme (FT100100238). Thanks to Sophie Wang, Su Gang and Su Xuezhong for assisting with data collection and to Ivan Roberts for reading early drafts.

\section{References}

Bao, Wanxian (2009) SOEs lead upsurge in charitable donations. China Daily, 23 March. Available at http://www.chinadaily.com.cn/bw/200903/23/content_7604326.htm, accessed 24 October 2014. 
Author copy, 1 July 2015, published in Asian Studies Review, 39, 4: 571-88 (DOI:10.1080/10357823.2015.1081871).

Bishop, Matthew and Michael Green (2008) Philanthrocapitalism: How the rich can save the world, and why we should let them (London: A. \& C. Black).

Carrillo, Beatriz (2012) Business opportunities and philanthropic initiatives: Private entrepreneurs, welfare provision and the prospects for social change in China. ProtoSociology 29, pp. 101-11.

Chakrabarty, Dipesh (2000) Provincializing Europe: Postcolonial thought and historical difference (Princeton: Princeton University Press).

'Charity law draft expected to be reviewed in 2015' (2015) Ecns.cn, 11 March. Online. Available: http://www.ecns.cn/cns-wire/2015/03-11/157641.shtml (accessed 10 June 2015).

Deng, Shasha (2011) Yushu earthquake donations well-supervised: Local official. Xinhua News Agency, 7 June. Available at http://news.xinhuanet.com/english2010/china/2011-07/06/c_13969489.htm, accessed 24 October 2014.

Edwards, Louise and Elaine Jeffreys, eds. (2010) Celebrity in China (Hong Kong: Hong Kong University Press).

Fitzgerald, John (2012) Supporting China's expanding non-profit sector, in Helmut Anheier and Bernard Lorentz (eds), Bridging the trust divide: Cultural diplomacy and fostering understanding between China and the West, pp. 75-80 (Berlin: Stiftung Mercator).

Forbes Staff (2011) Celebrity 100: How we create the list. Forbes.com, 18 May. Available at http://www.forbes.com/2011/05/17/celebrity-100-11-methodology.html, accessed 24 October 2014.

Fullbrook, David (2005) China, an emerging charity superpower. Asia Times Online, 16 February. 
Author copy, 1 July 2015, published in Asian Studies Review, 39, 4: 571-88 (DOI:10.1080/10357823.2015.1081871).

Goodman, David, ed. (2008) The new rich in China: Future rulers, present lives (Abingdon: Routledge).

Guowuyuan bangongting (2012) Guowuyuan bangongting guanyu yinfa Zhongguo ezhi yu fangzhi aizibing “shi'erwu' xingdong jihua de tongzhi guo banfa (2012) 4 hao, 13 January. Available at http://www.gov.cn/zwgk/2012-02/29/content_2079097.htm, accessed 24 October 2014.

He, Dan (2012) NGO: Deregulation for overseas charities "in the pipeline"; more funding for NGOs. China Daily, 21 August, p. 3.

Hi-pipe Talk Show Foundation (n.d.) Available at http://gov.eastday.com/hpqk/node7/index.html, accessed 24 October 2014.

Hildebrandt, Timothy (2011) The political economy of social organization registration in China. The China Quarterly 208, pp 970-89.

Jeffreys, Elaine (2011) Zhang Ziyi and China's celebrity philanthropy scandals. PORTAL Journal of Multidisciplinary International Studies 8(1), pp. 1-21.

Kapoor, Ilan (2013) Celebrity humanitarianism: The ideology of global charity (Abingdon: Routledge).

Li Ru (2009) Lun shehui bianqian Beijing xia shuyu 'cishan' de chuxian yu puji. Dalian Ligongdaxue Xuebao 30(4), pp. 90-4.

Lin, Liyao (2011) Top 25 charity foundations in China 2011. China.org.cn, 6 December. Available at http://www.china.org.cn/top10/201112/06/content_24048701_25.htm, accessed 24 October 2014. 
Author copy, 1 July 2015, published in Asian Studies Review, 39, 4: 571-88 (DOI:10.1080/10357823.2015.1081871).

Liu Weitao (2008) Hu Jintao: Fayang rendaozhuyi jingshen reqing canyu cishan huodong. Renmin Ribao, 6 December. Available at http://cpc.people.com.cn/GB/64093/64094/8471211.html, accessed 24 October 2014.

Ministry of Civil Affairs of the People's Republic of China (2013) 2012 nian shehui fuwu fazhan tongji gongbao. Mca.gov.cn, 19 June. Available at http://cws.mca.gov.cn/article/tjbg/201306/20130600474746.shtml, accessed 24 October 2014.

National People's Congress (2001) Zhonghua Renmin Gongheguo guomin jingji he shehui fazhan di shi ge wunian jihua gangyao, 15 March. Available at http://www.moc.gov.cn/zhuzhan/jiaotongguihua/guojiaguihua/guojiaxiangguan_ZHG H/200709/t20070927_420874.html, accessed 24 October 2014.

National People's Congress (2006) Zhonghua Renmin Gongheguo guomin jingji he shehui fazhan di shiyi ge wunian guihua gangyao, 16 March. Available at http://news.xinhuanet.com/misc/2006-03/16/content_4309517.htm, accessed 24 October 2014.

National People's Congress (2011) Zhonghua Renmin Gongheguo guomin jingji he shehui fazhan di shier ge wunian guihua gangyao, 16 March. Available at http://www.gov.cn/2011lh/content_1825838.htm, accessed 24 October 2014.

Ostrower, Francie (1995) Why the wealthy give: The culture of elite philanthropy (Princeton, NJ: Princeton University Press).

People's Daily (1946-present), Jinbao dianzi chuban zhongxin (Golden Newspaper Electrical Publishing Centre), Beijing; Oriprobe Information Services, Windsor, Canada. Available at http://www.oriprobe.com, accessed 30 September 2014.

Shieh, Shawn (2011) Preface, essential background on the nonprofit, philanthropic sector in China, and key findings. China Development Brief, pp. 2-8. 
Author copy, 1 July 2015, published in Asian Studies Review, 39, 4: 571-88 (DOI:10.1080/10357823.2015.1081871).

State Council (2004) Regulations on the Management of Foundations, issued 8 March 2004, effective 1 June 2004. Available at http://www.cecc.gov/resources/legalprovisions/regulations-on-the-management-of-foundations-chinese-text, accessed 24 October 2014.

Sun Yuemu (1994) Wei cishan zhengming. Renmin Ribao, 24 February, p. 4.

Thrall, A. Trevor, Jamie Lollio-Fakhreddine, Jon Berent, Lana Donnelly, Wes Herrin, Zachary Pacquette, Rebecca Wenglinski and Amy Wyatt (2008) Star power: Celebrity advocacy and the evolution of the public sphere. The International Journal of Press/Politics 13(4), pp. 362-85.

Wang, Zhuoqiong (2008) Quake triggers donation deluge. China Daily, 5 December. Available at http://www.chinadaily.com.cn/china/2008-12/05/content_7273896.htm, accessed 27 October 2014.

Watson, Andrew (2012) Building social welfare in China: Providing retirement incomes in a transforming economy, in Huw McKay and Song Ligang (eds), Rebalancing and sustaining growth in China, pp. 265-87 (Canberra: ANU ePress).

Wong, Linda (1994) Privatization of social welfare in post-Mao China. Asian Survey 34(4), pp. 307-25.

Wu Jing (2005) Guanzhu shou aizibing yingxiang ertong. Sina.com, 30 June. Available at http://news.sina.com.cn/o/2005-06-30/16346313809s.shtml, accessed 24 October 2014.

Xinhua News Agency (2010) Gates, Buffett dine with China's rich for charity. Xinhua News Agency, 30 September. Available at http://www.china.org.cn/world/201009/30/content_21039696.htm, accessed 24 October 2014.

Xu Li (2007) Guo Jingming ban zazhi bing jiang chengli cishan jijin zizhu pinkunsheng. Chengdu Wanbao, 11 January. Available at 
Author copy, 1 July 2015, published in Asian Studies Review, 39, 4: 571-88

(DOI:10.1080/10357823.2015.1081871).

http://news.163.com/07/0111/03/34HAGV8C00011229.html, accessed 24 October 2014.

Xue Xiaolu (dir.) (2010) Haiyang tiantang (Ocean Heaven) [Motion picture], PRC:

BDI Films Inc.

Zheng Ye (2004) Zhao Wei hui Wuhu laojia: Chengli Zhao Wei jiangxue zhuxue jijin. Beijing Qingnianbao, 7 December. Available at http://www.eduthinker.net/helper_detail/204.html, accessed 27 October 2014.

Zhou Qiuguang and Zeng Guilin (2006) Zhongguo cishan jianshi (Beijing: Renmin Chubanshe).

\section{Notes}

${ }^{1}$ The definition of philanthropy is contested. This definition is provided by Philanthropy Australia. Available at http://www.philanthropy.org.au/about-us/vision-and-mission/, accessed 24 October 2014.

${ }^{2}$ Guangzhou bans government staff from NGOs. Global Times, 28 October 2013, p. 5.

${ }^{3}$ Feng Gong (b. 1957, male operatic actor) in 1984, Cheng Lin (b. 1967, female singer) in 1997, and Shi Xiaolong (b. 1988, male child Kung Fu actor) in 1998.

${ }^{4}$ Foundation Source report presents findings about the 98 per cent "super-majority" of US private foundations in 2012. Philanthropy Journal, 29 May 2013. Available at http://www.philanthropyjournal.org/news/top-stories/foundation-source-report-presents-findings-about98-\%E2\%80\%9Csuper-majority\%E2\%80\%9D-us-private-fou, accessed 24 October 2014.

${ }^{5}$ Eight philanthropic initiatives have been created online, ostensibly by fans, in the name of five Chinese celebrities since 2005. The five celebrities are Han Xue, a female actor and singer; and four pop stars whose rise to fame is associated with "Chinese Idol" reality television programs - female singers Ji Minjia and Li Yuchun, and male singers Jing Boran and Zhang Jie.

${ }^{6}$ Zhao Wei. Tengxun Gongyi, 12 December 2010. Available at http://gongyi.qq.com/a/20101216/000150.htm, accessed 24 October 2014.

${ }^{7}$ Yangguang xingdong jijin. Zhongguo Yule Wang, 3 August 2011. Available at http://news.67.com/cishanquan/2011/08/03/279954.html, accessed 24 October 2014.

${ }^{8}$ China's 100 richest business people. Forbes, 1 December 2011. Available at http://www.forbes.com/global/2001/1112/032_61.html, accessed 24 October 2014.

${ }^{9}$ Dafu zibizheng guan'ai jijin. Zhongguo Yulewang, 1 August 2011. Available at http://news.67.com/cishanquan/2011/08/01/279834.html, accessed 24 October 2014. 